\title{
The role of organic matter amendment level on soil heating, organic acid accumulation, and development of bacterial communities in solarized soil
}

\author{
Christopher W. Simmons ${ }^{1}$, Brendan Higgins ${ }^{2}$, Simon Staley ${ }^{2}$, Lawrence D. Joh ${ }^{2}$, Blake A. \\ Simmons $^{3,4}$, Steven W. Singer ${ }^{3,4}$, James J. Stapleton ${ }^{5}$, and Jean S. VanderGheynst ${ }^{2,3 *}$
}
${ }^{1}$ Department of Food Science and Technology, University of California, Davis, CA 95616, USA
${ }^{2}$ Department of Biological and Agricultural Engineering, University of California, Davis, CA 95616, USA
${ }^{3}$ Joint BioEnergy Institute, Emeryville, CA 94608, USA
${ }^{4}$ Biological Systems and Engineering Division, Lawrence Berkeley National Laboratory, Berkeley, CA 94720, USA
${ }^{5}$ Statewide Integrated Pest Management Program, University of California, Kearney Agricultural Research and Extension Center, Parlier, CA 93648, USA

\author{
*Corresponding author: \\ Jean S. VanderGheynst \\ Department of Biological and Agricultural Engineering, One Shields Ave., Davis, CA 95616
}

Phone: 530-752-0989

e-mail: jsvander@ucdavis.edu 


\begin{abstract}
In light of the negative environmental impacts of soil fumigants such as methyl bromide, soil solarization, the treatment of soil using passive solar heating, has emerged as an environmentally friendly approach to soil pest suppression. Unfortunately, traditional solarization processes remove land from cultivation for 4-6 weeks during the peak of the growing season, limiting their economic practicality. Biosolarization, where soil is amended with organic residues prior to solarization, can accelerate pest suppression, compress the solarization timetable, and facilitate effective treatment in shorter time periods. A combination of laboratory experiments and a field trial were employed in this study to examine the effects of organic matter amendment on soil heating, organic acid accumulation, and microbial community dynamics during biosolarization. Provision of organic matter resulted in robust metabolic activity, boosting peak soil temperatures by up to $2{ }^{\circ} \mathrm{C}$ beyond what could be achieved without an organic amendment. In the deep soil layers, organic matter amendment led to significant accumulation of acetic, iso-butyric, and butyric acids; increasing organic matter from $0 \%$ to $5 \%$ yielded 352 to 1271 fold increases in organic acid accumulation. The relative abundance of several organisms belonging to the phylum Firmicutes also increased with increasing organic matter amendment. The organic acid levels observed in this study (1-7 $\mathrm{mg} \mathrm{g}^{-1}$ soil) would result in soil suppressive to a variety of fungal and nematode plant pathogens. Moreover, results suggest that suppression could be achieved within 2 weeks, potentially making biosolarization a more attractive alternative to chemical fumigation.
\end{abstract}

Keywords: biosolarization, heat generation, compost, soil amendment, organic acid, microbial community structure 


\section{Introduction}

Soil fumigation with synthetic chemicals is a common and effective agricultural practice for economic control of soilborne pathogens, nematodes, and weeds. Methyl bromide is one fumigant that has been used for maximizing production of high-value specialty crops, however, its use contributes to significant stratospheric ozone depletion and it has been largely phased out of routine usage (USEPA, 2011). The alternatives adopted by many growers have been other synthetic toxicants, including 1,3-dichloropropene, chloropicrin, metam sodium, metam potassium, dazomet, and sodium tetrathiocarbonate. These toxicants have significant problems of their own, including release of volatile organic compounds (VOCs) into the atmosphere, acute mammalian toxicity, and potential for ground and surface water contamination, which has led to usage caps and other governmental regulatory actions (EPA, 2012).

Soil solarization is a safe and effective, non-chemical alternative to fumigation. During soil solarization, moist soil is covered with a transparent plastic tarp, resulting in passive solar heating of the soil and a pasteurization effect that reduces pathogen populations. Despite this benefit, solarization is only applied commercially to a limited extent, because the recommended solarization duration is 4-6 weeks during the warmest period of summer (Elmore et al., 1997) and most growers cannot justify taking cropland out of production for that length of time.

Researchers have shown that solarization effectiveness can be increased, thereby decreasing treatment duration, if solarization is combined with other plant disease control techniques, such as incorporation of cruciferous residues (Ramirez-Villapudua and Munnecke, 1988), or application of compost (Gamliel and Stapleton, 1993). Soil organic matter amendment may improve the efficacy of solarization by increasing soil temperatures during solarization; soil temperatures have been reported to be $2-3{ }^{\circ} \mathrm{C}$ higher during solarization with compost than 
without compost (Gamliel and Stapleton, 1993), as a result of exothermic microbial activity stimulated by organic matter application (Simmons et al., 2013).

While addition of organic matter improves soil heating, organic matter decomposition during the solarization process is poorly understood. For example, there is little information on the evolution and accumulation of organic acids during the solarization process and the impact of changes in organic matter composition on microbial community structure. This information is important in order to best manage organic matter amendment and solarization conditions to achieve rapid soil heating while minimizing potential phytotoxic effects of residual organic acids on solarized soil.

In this study we examined the effect of amended organic matter level on organic acid accumulation, soil heating, and microbial community structure during soil solarization. Laboratory studies were conducted in temperature-controlled incubators to determine stable compost and organic matter amendment levels needed to achieve elevated biological activity. These studies were followed by a field experiment to evaluate laboratory observations. Soil biological activity and compost stability were characterized by measuring respiration and organic acid accumulation while microbial community structure was analyzed by high-throughput $16 \mathrm{~S}$ rRNA gene sequencing. The results demonstrate the role organic matter management plays on temperature elevation and organic acid accumulation, potential key factors involved with soil disinfestation.

\section{Materials and methods}

\subsection{Soil and compost preparation}

Dry topsoil (Hanford sandy loam) was collected July 2011 from the 0-15 cm depth range at UC Kearney Agricultural Research and Extension Center (KARE) in Parlier, CA (36.6 ${ }^{\circ} \mathrm{N}$; 
$119.5^{\circ} \mathrm{W}$; elevation $97 \mathrm{~m}$ a.s.1.), sieved through a $3.18 \mathrm{~mm}$ screen, and stored at room temperature. The soil was classified as Hanford fine sandy loam and the contents of organic matter, sand, silt, and clay were $0.0151 \mathrm{~g}(\mathrm{dry} \mathrm{g})^{-1}, 0.41 \mathrm{~g}(\mathrm{dry} \mathrm{g})^{-1}, 0.37 \mathrm{~g}(\mathrm{dry} \mathrm{g})^{-1}$ and $0.22 \mathrm{~g}$ $\left(\right.$ dry g) ${ }^{-1}$, respectively (Marshall et al., 2013). Varying levels of compost stability were achieved by preparing compost mixtures containing stable green waste compost, and varying amounts of autoclaved wheat bran (Simmons et al., 2013). This was done to maintain a consistent microbial inoculum associated with the compost while enabling control of organic matter level and the potential for biological activity in the amended soil. Wheat bran was selected because its composition is similar to agricultural residues and municipal solid waste. Green waste compost was collected in May 2012 from Northern Recycling in Yolo County, CA. Compost was air dried under ambient conditions to a moisture content of 30.2\% (dry weight basis), sealed in plastic bins, and stored at room temperature (ca. $21-28^{\circ} \mathrm{C}$ ). Food grade wheat bran ('Giusto's Vita Grain,' South San Francisco, CA) was autoclaved dry at $121^{\circ} \mathrm{C}$ for 20 minutes. The sterile wheat bran (11.7\% moisture content, dry basis) was then sealed in plastic bags and stored at room temperature.

\subsection{Microcosm preparation}

To prepare soil mixtures for field trial microcosms, soil wetted to field capacity was collected from the trial site and sieved through a $3.18 \mathrm{~mm}$ screen, and compost and wheat bran were wetted separately to $80 \%$ of field capacity the day prior to solarization. Field capacities for soil, compost, and wheat bran were $12 \%$ dry basis, $87 \%$ dry basis, and $172 \%$ dry basis, respectively. Wetted soil, compost, and wheat bran were combined to achieve the three following soil mixtures: (1) 98\% soil and 2\% compost (dry weight basis), (2) 96\% soil, $2 \%$ compost, and 2\% wheat bran, and (3) 93\% soil, $2 \%$ compost, and 5\% wheat bran. Soil mixtures 
were allowed to equilibrate for approximately 12 hours under ambient conditions. Equilibrated soil mixtures were packed into $3.8 \mathrm{~L}$ black plastic Grow Bags with drainage holes to facilitate moisture and gas exchange (neHydro, Southampton, MA) to form microcosms. Temperature sensors (model 1922L, iButtonlink, Whitewater, WI) were embedded in the center of each microcosm at a depth $12.7 \mathrm{~cm}$. The diameter and height of filled microcosms were $17.8 \mathrm{~cm}$ and $17.4 \mathrm{~cm}$, respectively.

\subsection{Solarization}

The KARE field site used for soil collection was also used for conducting the field experiment. The field site was summer-cropped with sunflower in 2007, left fallow in 2008, and cropped with a winter forage mix (approximately 50\% oats, 25\% beardless barley, and 25\% beardless wheat) in 2009 and 2010. Cool-season weed covers were present during portions of each year. To prepare for the solarization experiment, the field was plowed in May 2011 to incorporate the remains of the forage mix. The field was then irrigated, dried down, disced twice, then rotovated to bring soil to seedbed texture. Finally, an orchard float was passed over the soil to smooth the soil surface sufficiently for plastic film application. Solid-set sprinklers were placed around the plot and the site was irrigated five, three, and one day prior, as well as immediately before the initiation of the experiment. Pre-experiment water application totaled approximately $6.5 \mathrm{~cm}$, which was sufficient to bring the soil to above field capacity at depths sampled in this study.

The experimental design for field plots followed those from prior field trials (Simmons et al., 2013). The field site was arranged into 5 plots. Each plot contained each of the three microcosms with soil amended with compost and wheat bran. Microcosms were buried within 
plots such that the top of the microcosm was flush with the soil line. Microcosms were buried $0.6 \mathrm{~m}$ apart from each other with a $0.9 \mathrm{~m}$ buffer between microcosms and plot borders. Microcosms were arranged randomly within each plot. Plots were covered with 0.7 mil transparent plastic sheets ('Husky Film Sheeting,' Poly-America, Inc., Grand Prairie, TX) and sheet edges were embedded in soil along plot borders to begin solarization. Temperature was logged every 15 minutes during solarization. After 15 days of solarization, microcosms were exhumed from field plots at 06:00-07:00 hours, and were immediately transported at ambient conditions for approximately 3 hours from the field site to the laboratory. Upon arrival, microcosms were cut into three $5.8 \mathrm{~cm}$ sections to isolate soil samples from various depths. Soil sections were sealed in plastic bags and stored at $-20{ }^{\circ} \mathrm{C}$ until analysis of residual respiration, organic acid concentration and 16S rRNA gene sequencing

\subsection{Laboratory incubations and respiration measurement}

Laboratory studies were performed to examine the role of compost inoculum on respiration in soil amended with organic matter. Field soil was amended with varying amounts of green waste compost $(0,2$, and 5\%, dry weight basis) and heat-sterilized wheat bran $(0,2$, and $5 \%$, dry weight basis), wetted to $80 \%$ of water holding capacity, and incubated for 8 days in 250 $\mathrm{ml}$ bioreactors aerated at $20 \mathrm{ml} \mathrm{min}{ }^{-1}$ under a diurnal cycle $\left(16 \mathrm{hrs}\right.$ at $50{ }^{\circ} \mathrm{C}, 8 \mathrm{hrs}$ at $\left.25^{\circ} \mathrm{C}\right)$ meant to simulate solarization temperatures (Simmons et al., 2013).

Respiration measurements were also performed on $30 \mathrm{~g}$ samples (dry weight basis) of each soil mixture returned from field experiments to determine stability before and after solarization. Samples were placed into $250 \mathrm{ml}$ bioreactors as previously described (Aslam and VanderGheynst, 2008). Three bioreactors (one for each soil depth sampled) were run for each 
microcosm recovered from the field. Reactors containing soil from field experiments were supplied with air at a rate of $20 \mathrm{ml} \mathrm{min}{ }^{-1}$ and incubated at $35{ }^{\circ} \mathrm{C}$. Distilled water was added to reactors periodically to maintain initial moisture contents.

Carbon dioxide concentrations in reactor influents and effluents were measured using an infrared $\mathrm{CO}_{2}$ sensor (Vaisala, Suffolk, UK) and mass flow rate through reactors was measured using a mass flow meter (Aalborg, Orangeburg, NY). Carbon dioxide and mass flow measurements were taken approximately every 5 hours for each bioreactor. Carbon dioxide evolution rate and cumulative respiration (cCER) were calculated as described previously (Simmons et al., 2013). The maximum predicted cumulative respiration (cCERmax) was calculated by fitting a saturation model to cCER versus time data using the non-linear fit command in Matlab (version 7.4.0.739, MathWorks, Natick, MA) as described elsewhere (Achmon et al., 2016).

\subsection{Estimation of soil heating}

Soil heating was estimated following procedures described elsewhere (Simmons et al., 2013). Briefly, specific heat capacity values for soil mixtures were calculated from the specific heat capacities of mixture components. Specific heat capacity values for dry soil $\left(0.8 \mathrm{~J} \mathrm{~g}^{-1}{ }^{\circ} \mathrm{C}^{-1}\right)$ and compost $\left(0.42 \mathrm{~J} \mathrm{~g}^{-1}{ }^{\circ} \mathrm{C}^{-1}\right)$ were estimated from standard values for soil and lignocellulosic material, respectively (Irvine et al., 2010). The specific heat capacity of wheat bran $\left(1.3 \mathrm{~J} \mathrm{~g}^{-1}{ }^{\circ} \mathrm{C}^{-}\right.$

${ }^{1}$ ) was estimated from that of rice bran (Sreenarayanan, 1986). The specific heat capacity of each mixture was calculated as the sum of products obtained from multiplying each component's specific heat capacity by the mass fraction of the component in the mixture including water. The bulk density of the soil + compost mixtures containing $5 \% 2 \%$, and $0 \%$ wheat bran were 1.63 , 
1.75 , and $1.9 \mathrm{~g} \mathrm{ml}^{-1}$, respectively; because wheat bran has a greater water holding capacity than soil, the mixture moisture contents were $25 \%, 19 \%$, and $14 \%$ (wet basis), respectively. These yielded a mixture heat capacity for the soil + compost mixtures containing 5\%, $2 \%$, and $0 \%$ wheat bran of $2.69 \mathrm{~J} \mathrm{ml}^{-1}{ }^{\circ} \mathrm{C}^{-1}, 2.54 \mathrm{~J} \mathrm{ml}^{-1}{ }^{\circ} \mathrm{C}^{-1}$, and $2.39 \mathrm{~J} \mathrm{ml}^{-1}{ }^{\circ} \mathrm{C}^{-1}$, respectively. Soil heating was calculated as

$$
q=\int_{0}^{t} \rho_{b} c_{p} \frac{d T}{d t} d t
$$

where $q$ is the heat added to the soil mixture $\left(\mathrm{J} \mathrm{ml}^{-1}\right), \rho_{\mathrm{b}}$ is the bulk density of the wetted soil mixture $\left(\mathrm{g} \mathrm{ml}^{-1}\right), c_{\mathrm{p}}$ is the specific heat capacity of the mixture $\left(\mathrm{J} / \mathrm{g} /{ }^{\circ} \mathrm{C}\right)$, and $T$ is the measured temperature of the soil mixture $\left({ }^{\circ} \mathrm{C}\right)$. Temperature change with respect to time $(t)$ was calculated using the central difference method. Constant specific heat capacity and soil moisture content were assumed, given the temperature range of solarization, the excess of saturated soil surrounding the microcosms, and the plastic tarp preventing evaporation.

\subsection{Organic acid extraction and analysis}

Water extracts of solarized samples were prepared by shaking the samples in DI water with a 2:1 mass dilution $\left(\mathrm{H}_{2} \mathrm{O}\right.$ : sample) for $30 \mathrm{~min}$. The mixtures were centrifuged at 12,000 $\mathrm{g}$ for $10 \mathrm{~min}$, and then the supernatants were filtered through $0.2 \mu \mathrm{m}$ PTFE syringe filters. The resulting filtrates were used to measure organic acids using an HPLC (Shimadzu, Columbia, MD) equipped with an ion exchange column (Bio-Rad Aminex HPX-87H, 300×7.8 mm) and a UV detector (SPD-20A Prominence, Shimadzu, Columbia, MD) for identifying organic acids. Before HPLC measurement, filtered extracts were acidified with 1:1 $10 \mathrm{mM}$ sulfuric acid in 
Milli-Q water. The mobile phase was $5 \mathrm{mM}$ sulfuric acid in Milli-Q water with a flow rate of 0.6 $\mathrm{ml} \mathrm{min}{ }^{-1}$ and the column oven was $60{ }^{\circ} \mathrm{C}$. A wavelength of $210 \mathrm{~nm}$ was used for the $\mathrm{UV}$ detector.

\subsection{DNA extraction and 16S rDNA sequencing}

Microbial DNA was extracted from solarized soil samples using a Powersoil DNA Isolation Kit (MO-BIO, Carlsbad, CA). Soil samples were well-mixed prior to DNA extraction. Duplicate extractions were performed for each sample and the purified DNA was pooled. Sequences corresponding to the 16S rRNA gene were amplified from DNA extracts using PCR. Sequencing of the V4 hypervariable region of the broadly conserved 16S rRNA gene was performed on purified DNA by the United States Department of Energy Joint Genome Institute using the Illumina MiSeq platform, as previously described (Simmons et al., 2014).

\subsection{Analysis of iTag sequences}

OTU counts from 16S rRNA gene sequencing, obtained from the Illumina MiSeq platform, were filtered to remove singletons as well as data from rodent-disturbed plots. The Vegan package in $\mathrm{R}$ was used to determine Bray-Curtis dissimilarity between communities obtained from different plots, organic amendment, and soil depth. Non-metric multidimensional scaling (NMDS) was conducted using the Vegan package to generate a 2D representation of the Bray-Curtis dissimilarity matrix based on 1,000 random starts. 9562 OTUs ( $97 \%$ minimum identity) were identified across all plots, of which, the 2600 most abundant OTUs were retained for further analysis. This subset represented $>95 \%$ of organism abundance among analyzed samples. SIMPER analysis was then carried out to determine which specific OTUs were contributing most to this observed dissimilarity. Multiple SIMPER analyses were carried out across comparisons based on depth and wheat bran concentration. A group of 19 OTUs were 
identified that contributed to large differences in Bray-Curtis dissimilarity across comparisons based on soil depth and wheat bran concentration.

\section{Results}

\subsection{Effect of compost and organic matter amendment on microbial activity}

Laboratory studies were performed to examine the role of compost inoculum on respiration in soil amended with organic matter. In $2 \%$ wheat bran treatments, the rate of activity during the first two days of simulated solarization was approximately $25 \%$ greater in the treatments with compost compared to the treatment with only wheat bran (Figure 1A). In 5\% wheat bran treatments the rate of activity during the first two days of simulated solarization was approximately 50\% greater in treatments containing compost compared to the treatment with only wheat bran (Figure 1B). The results indicate that addition of green waste compost enhanced the initial rate of organic matter decomposition. The enhanced respiration associated with compost addition persisted throughout the 8-day experiment. Increasing the compost level beyond 2\% did not increase respiration and therefore field trials were completed with $2 \%$ compost amendment.

\subsection{Heating of soils amended with compost and organic matter}

Five of the fifteen microcosms were compromised during the field trial due to a unidentified vertebrate scavenger. Consequently, no data are included for microcosms in plots 2 and 4 , as well as the $2 \%$ wheat bran in plot 1 . Temperature data from microcosms that were not disrupted are presented in Figure 2. The first seven days are presented and show temperature profiles for each treatment. The average microcosm temperature at $12.7 \mathrm{~cm}$ depth varied between $30{ }^{\circ} \mathrm{C}$ and $45^{\circ} \mathrm{C}$. In general, peak and minimum temperatures were greatest for 
microcosms containing $5 \%$ wheat bran followed by microcosms containing $2 \%$ wheat bran.

Maximum temperatures occurred between 17:00 and 21:00 hr (evening) and minimum

temperatures occurred between 8:00 and 10:00 hr (morning).

Although the addition of wheat bran increased plot temperatures on average, there were marked differences in the performance of individual plots. Temperature and heating differences between soil amended with compost and wheat bran and soil amended with only compost were calculated to show the extent of temperature and heating augmentation by the addition of wheat bran (Figures 3 and 4). For treatments containing 5\% wheat bran, temperature differences were almost always greater than zero with the exception of plot 3 in which temperature differences less than zero were observed on days 4-10, but for only a small portion of each day (Figure 3B). Increased wheat bran amendment particularly increased the peak daily temperature where differences were always above zero for both $2 \%$ and $5 \%$ wheat bran. In contrast, wheat bran amendment had little effect on temperature minimums where differences were close to zero and occasionally negative.

Heating differences for microcosms in plots 1, 3, and 5 (Figure 4) show similar trends to the temperature data. Heating differences were greatest for treatments containing 5\% wheat bran with differences ranging from $0-1.5 \mathrm{~J} \mathrm{ml}^{-1}$ for plot $1,-1.8-2.1 \mathrm{~J} \mathrm{ml}^{-1}$ for plot 3 , and -1.4-3.2 $\mathrm{J} \mathrm{ml}^{-1}$ for plot 5. Consistent with the temperature data, wheat bran amendment generally increased soil heating when soil temperatures were highest.

\subsection{Residual respiration}

In order to determine the extent of organic material decomposition during biosolarization, soil samples were analyzed for their residual respiration potential as indicated by fitted values for cCERmax, the asymptote in cCER versus time data. Figure 5 shows cumulative 
respiration for freshly prepared soil + compost + wheat bran mixtures and for samples collected from solarized microcosms. The soil containing only compost contained very little readily degradable organic matter and resulted in the lowest respiration rate. As expected, soil amended with wheat bran yielded higher respiration that increased with increasing wheat bran amendment.

Exhaustion of the degradable organic matter varied with treatment and soil depth. For treatments containing $2 \%$ wheat bran, about $55 \%$ of the respiration activity in the top $(0-5.8 \mathrm{~cm})$ layer was exhausted while only $25 \%$ was exhausted from the bottom $(11.6-17.4 \mathrm{~cm})$ layer during the fifteen days of solarization. In treatments containing 5\% wheat bran, about $60 \%$ of the respiration activity in the top layer was exhausted while only $25-30 \%$ was exhausted from the bottom layer. This indicates that microbes in the top layer were better able to metabolize the amendment.

\subsection{Organic acid accumulation in solarized soils amended with organic matter}

Organic acids that were detected by HPLC in solarized samples included acetic, isobutyric, and butyric acids (Figure 6). No formic, lactic, or propionic acid could be detected. Organic acid levels were lowest in samples containing only compost and increased with increasing wheat bran amendment (Figure 6). For instance, increasing wheat bran from $0 \%$ to $5 \%$ in the bottom layer $(14.8 \mathrm{~cm}$ average depth) yielded increases of 1184,1271 , and 352 fold in total organic acid content for plots 1, 3, and 5, respectively (Table S1). For plots 3 and 5, increasing wheat bran amendment from $2 \%$ to $5 \%$ resulted in 6.6 and 3.7 fold increases in total organic acid content, respectively.

Within a given plot, the lowest levels of organic acids detected tended to be in the top soil layer (2.96 cm depth) closest to the soil-tarp interface where aerobic conditions are most likely to prevail. In the deep soil layer, 55-58\% of organic acid accumulation was in the form of acetic 
acid across plots 1, 3, and 5. Iso-butyric acid constituted 16.1-17.7\% and butyric acid constituted $24.7-28.7 \%$ of total organic acid in these same plots.

Marked variability in total organic acid accumulation was observed among plots even though the organic acid composition was quite consistent. This variability was most pronounced in the deep soil layers where plot 3 had roughly five fold greater total organic acid content than plot 5 (Table S1).

\subsection{Changes in microbial community composition and diversity}

We analyzed the microbial communities through sequencing of the 16S rRNA gene as a marker to better understand which organisms respond to wheat bran under the thermophilic conditions of biosolarization. Despite the differences in total organic acid concentrations, the microbial community compositions were quite consistent across the microscosms from plots 1,3 , and 5. However, sequencing results revealed marked differences among soils supplemented with different quantities of wheat bran. The initial community structure at the outset of solarization was similar for all amendment treatments (Figure 7). Community restructuring was observed across all treatments following solarization, although the magnitude depended on amendment level and soil depth. In general, solarized soil lacking wheat bran exhibited the lowest degree of restructuring compared to the initial community state. For this treatment, a gradient of dissimilarity was observed with respect to the initial community structure. Communities deeper in the soil were more similar to the initial community compared to those near the soil surface. In contrast, soils containing $2 \%$ and $5 \%$ wheat bran showed a more radical shift in community structure following solarizaiton (Figure 7). As with soil containing $0 \%$ wheat bran, a clear distinction in community structure was observed in bran-amended soil for each depth tested. However, unlike soil lacking wheat bran, there was no particular depth at which the communities 
in bran-amended soils remained more similar to the initial state. While soil containing $2 \%$ and $5 \%$ wheat bran showed similar shifts in community structure, soil with $5 \%$ wheat bran generally exhibited greater dissimilarity from the initial state.

SIMPER analysis of the metagenome further revealed which organisms were contributing to these differences in microbial community structure based on soil depth and wheat bran treatment. In soils without wheat bran supplementation, organisms belonging to class Gemmatimonadetes, genus Steroidobacter, genus Cytophaga, class Chloracidobacteria, and genus Streptomyces were dominant. Wheat bran supplementation resulted in a significant decline in relative abundances of these organisms $(\mathrm{p}<0.03$ for all organisms, $\mathrm{t}$-test comparing $0 \%$ to $2 \%$ and $0 \%$ to $5 \%$ amendment) regardless of soil depth (Table 1).

In the middle and deep soil layers, several organisms from the families Ruminococcaceae, Lachnospiraceae, and Bacillaceae had significantly higher relative abundances $(\mathrm{p}<0.05)$ when wheat bran was added. For each of these families, we observed a stepped increase in their abundance with increasing wheat bran content. This indicated that the effect of wheat bran was a function of its concentration, at least up to 5\%. Moreover, wheat bran supplementation in the middle and deep layers reduced community diversity such that only nine organisms accounted for over $66 \%$ of the community in plots amended with $5 \%$ wheat bran. In those same soil layers without wheat bran supplementation, the top 19 organsims only accounted for $24 \%$ of the community. In the top soil layer, wheat bran amendment led to increases in Lachnospiraceae and Bacillaceae but not Ruminococcaceae.

Given its strong effect on the microbial community, we analyzed the $5 \%$ wheat bran samples in more detail to better understand the effect of soil depth on the microbial community in the presence of organic amendment. Such data may help to explain the observed heterogeneity 
in organic acid concentration among the soil layers. Here too, we found large differences in community structure based on soil depth (Table 2). Ruminococcaceae were the dominant organism in the deep layer, representing roughly $40 \%$ of the total community. In the middle and top layers, members of Bacillaceae became increasingly abundant, particularly Ureibacillus. Interestingly, Geobacillus was among the dominant OTUs in the middle layer but not in the top layer.

\section{Discussion}

Variations in heating differences can be attributed to soil thermal and physical properties and biochemical reactions occurring in the soil, both within microcosms and the surrounding, open soil, during soil treatment. Consistent with previous studies (Simmons et al., 2013), we found that adding an organic amendment to soil during solarization increased soil temperatures. Specifically, we found that amending with wheat bran boosted soil heating when soil temperatures were highest, suggesting that solar heating stimulated microbial activity. This enhanced metabolic activity then amplified the peak soil temperature, which would likely improve pest and propagule damage.

In the field trial, the majority of wheat bran metabolism occurred in the soil layer near the surface. We hypothesize that this is due largely to the aerobic conditions and higher temperatures that likely prevailed in this layer. Bacillaceae, particularly Ureibacillus, were dominant in the top soil layer under 5\% wheat bran conditions. Members of Ureibacillus are recognized to be thermophilic, obligate aerobes, and several species have been shown to degrade lignocellulosic biomass, features which are consistent with growth near the soil surface during biosolarization.

Less wheat bran was consumed in the middle and deep layers where temperatures were likely cooler and conditions were anaerobic. Members of the phylum Firmicutes and of the 
families Ruminococcaceae and Lachnospiraceae and of the genus Geobacillus, were the dominant organisms in the middle and deep soil layers under high (5\%) wheat bran loading. Together, the relative abundance of these organisms comprised more than half of the abundance in the deep layer and more than a third in the middle soil layer. Research by others has shown that members from all three of these taxa are capable of degrading lignocellulosic biomass (Bhalla et al., 2013; Biddle et al., 2013; Vital et al., 2014; Zainudin et al., 2013) and that many strains are rich in glycoside hydrolases (Bhalla et al., 2013; Biddle et al., 2013).

The families Ruminococcaceae and Lachnospiraceae also contain a variety of species capable of producing butyric acid and are likely major contributors to the observed accumulation of butyric acid in the deep soil layers supplemented with wheat bran. The accumulation of organic acids in the middle and deep soil layers suggest an anaerobic environment and, indeed, Ruminococcaceae and Lachnospiraceae are known to be strict anaerobes (Biddle et al., 2013). Interestingly, we observed relatively high abundance of Lachnospiraceae in the top soil layer suggesting that this particular taxa may instead be a facultative anaerobe.

Acetic acid and butyric acid both have the ability to suppress soil pests and pathogens. Acetic acid is known to suppress plant fungal pathogens and Doran (Doran, 1928) showed that its inhibitory properties are not simply due to a change in $\mathrm{pH}$. Likewise, butyric acid is known to suppress a variety of plant fungal pathogens as well as nematodes. Browning et al. (Browning et al., 2006) showed that as little as $0.88 \mathrm{mg}$ butyrate per gram of soil could kill the fungal pathogens Verticillium dahliae, Rhizoctonia fragariae, $R$. solani, Phytophthora fragariae, and a Pythium sp. within two days of treatment. Gall nematode reduction of $73-100 \%$ was achieved in sand that was treated with either 0.88 or $8.8 \mathrm{mg}$ butyrate per gram sand. Likewise, McElderry et al. (McElderry et al., 2005) showed that soil amended with just $0.88 \mu \mathrm{g} / \mathrm{g}$ soil was sufficient to 
kill all Tylenchorhynchus spp. nematodes. Like Doran, McElderry et al. found that the suppressive effect was not due to a change in $\mathrm{pH}$ but rather to characteristics of the organic acids.

One concern regarding use of organic acids for pathogen suppression is their relatively short residence time in the soil due to their high volatility (Browning et al., 2006). The upside of the short residence time is that organic acids can leave the soil quickly, alleviating suppression of crop growth. The advantage of biosolarization is that plastic tarps can help trap organic acids and other biotoxic decomposition products in the soil (Gamliel and Stapleton, 1993; Momma et al.). Moreover, the breakdown of lignocellulose by organic acid-producing bacteria, leads to ongoing generation of organic acids over time, in contrast to a one-time application of organic acids to the soil. The challenge faced in the present study was inconsistency in organic acid accumulation among different treatment plots. This occurred in spite of consistent microbial communities among plots 1,3 , and 5 suggesting that organic acids may have been generated but were somehow lost, perhaps due to leakage to the atmosphere in certain microcosms, consumption by microorganisms, or small differences in soil compaction and drainage among microcosms. Plot 5 in particular had low organic acid content accompanied by high metabolic heating indicative of greater aerobic activity, potentially resulting from a gap in the tarp or differences in soil compaction during microcosm preparation. Thus management of site preparation is critical not only for solar heating but also for organic acid accumulation and retention.

One third of the microcosms in this study were disturbed by an infestation, resulting in damage to the plastic tarp and likely release of organic acids. We suspect that fermentation odors generated by biosolarization attracted vertabrates and thus measures should be taken to ensure that plots are undisturbed during the biosolarization process. Despite these challenges, several biosolarization plots supplemented with 5\% wheat bran resulted in 1-7 mg organic acid/g soil in 
the bottom soil layer. Butyric and isobutyric acid accounted for $0.4-3.1 \mathrm{mg} / \mathrm{g}$ soil in these same samples while acetic acid made up the balance. These concentrations are likely sufficient to inactivate a variety of plant pathogens such as those discussed by Browning et al. (2006).

More recently, Kim et al. (Kim et al., 2007) supplemented soil with wheat bran and covered the soil with plastic to achieve an anaerobic state. They observed significant production of both acetic $(\sim 30 \mathrm{mM})$ and butyric $(\sim 25 \mathrm{mM})$ acids and found that these concentrations were sufficient to suppress a variety of plant fungal pathogens. Unlike our study, however, they did not solarize the soil at the same time so pathogen suppression was due only to production of organic acids, and perhaps other, unassayed biotoxic compounds. In our case, acetic acid and butyric acid concentrations were on the order of 0.5-3.8 $\mathrm{mg}$ acetic acid and 0.25-1.98 mg butyric acid per gram soil in the bottom layers of the $5 \%$ wheat bran microcosms. At $25 \%$ moisture content (wet basis) these mass fractions convert to 25-190 mM acetic acid and 5.3-37.9 mM butyric acid, respectively, concentrations that are on par with those of Kim et al. Moreover, the augmented heat of bio-solarization combined with the suppressive characteristics of organic acids and other biotoxic decomposition products may lead to rapid soil disinfestation.

The combined disinfection power of organic acids and enhanced heating suggest that biosolarization could significantly cut solarization time from weeks to days. Further research needs to be carried out to assess the durability of the microbial community after solarization occurs. Many of the Firmicutes observed in the deep layers of the solarized plots bear similarity to microbes found in mammalian gut environments: Ruminococcaceae and Lachnospiraceae are both known to contribute to pathogen suppression in the human intestine (Biddle et al., 2013). If these organisms can persist after solarization and continue to decompose the residual wheat bran, they may continue to provide limited pathogen-suppression capability. 


\section{Conclusions}

Biosolarization, in which soils were amended with wheat bran, led to elevated soil heating beyond that achieved using passive solarization. Moreover, this elevated heating coincided with high soil temperatures, suggesting that microbial metabolism increased in response to solar heating. The result was an amplification of peak temperatures which should aid in soil disinfestation. In the deeper soil layers, biosolarization also resulted in organism selection and anaerobic conditions conducive to organic acid production. The post-solarization concentrations of acetic and butyric acids in particular should be sufficient to inactivate a variety of plant pathogens within a matter of days. Rapid disinfestation is critical for the widespread adoption of bio-solarization as an effective and sustainable alternative to chemical soil fumigation.

\section{Acknowledgements}

The authors thank Dr. Ruth Dahlquist, Lauren Jabusch and Josh Claypool for assistance with the solarization field experiments, Charles Karagosian for preparation of compost, and Dr. Michael Raviv at Newe Ya'ar Research Center at the Agricultural Research Organization of Israel, for discussions related to field experiments. This work was funded by the United StatesIsrael Binational Agricultural Research and Development Fund \#US-4266-09 R, National Institute of Food and Agriculture project CA-D-BAE-2228-RR, the UC Laboratory Fees Research Program \#12-LR-237496, and was performed as part of the DOE Joint BioEnergy Institute (http://www.jbei.org) supported by the U.S. Department of Energy, Office of Science, Office of Biological and Environmental Research, through contract DE-AC02-05CH11231 between Lawrence Berkeley National Laboratory and the U.S. Department of Energy. The financial sponsors of this work had no role in study design; in the collection, analysis and 
interpretation of data; in the writing of the article; and in the decision to submit the article for publication. 16S rRNA gene sequencing was conducted by the Joint Genome Institute, which is supported by the Office of Science of the U.S. Department of Energy under Contract No. DEAC02-05CH11231. 


\section{List of Figures}

Figure 1. Cumulative respiration (cCER) for soil amended with wheat bran and varying levels of compost during simulated solarization. (A) Soil amended with 2\% wheat bran. (B) Soil amended with 5\% wheat bran. C: compost; WB: wheat bran.

Figure 2. Mean soil temperature during solarization for field soil amended with varying levels of wheat bran. $2 \mathrm{C} 0 \mathrm{~W}: 2 \%$ compost, $2 \mathrm{C} 2 \mathrm{~W}: 2 \%$ compost $+2 \%$ wheat bran, and $2 \mathrm{C} 5 \mathrm{~W}: 2 \%$ compost $+5 \%$ wheat bran. The lines for $2 \mathrm{C} 0 \mathrm{~W}, 2 \mathrm{C} 2 \mathrm{~W}$, and $2 \mathrm{C} 5 \mathrm{~W}$ represent the averages of five microcosms, two microcosms (plots 3 and 5) and three microcosms (plots 1, 3, and 5), respectively.

Figure 3. Soil temperature difference during solarization for field soil amended with varying levels of lignocellulose. Temperature difference was calculated by subtracting the temperature of treatments containing wheat bran from treatments containing only compost. (A) Temperature difference for microcosms containing $2 \%$ compost $+2 \%$ wheat bran. (B) Temperature difference for microcosms containing $2 \%$ compost $+5 \%$ wheat bran.

Figure 4. Soil heating difference during solarization for field soil amended with varying levels of lignocellulose. Heating difference was calculated by subtracting the heating of treatments containing wheat bran from treatments containing only compost. (A) Heating difference for microcosms containing $2 \%$ compost $+2 \%$ wheat bran. (B) Heating difference for microcosms containing $2 \%$ compost $+5 \%$ wheat bran. 
Figure 5. Average residual respiration for soil mixtures after 15 days of solarization. Values are presented only for samples that yielded sufficient cCER (cumulative respiration) versus time data for fitting of cCERmax (maximum cumulative respiration). Respiration is measured as carbon dioxide evolved per gram of dry soil.

Figure 6. Organic acid content for soil mixtures averaged across plots 1, 3 and 5 (except for 2\% wheat bran where only plots 3 and 5 are included) after 15 days of solarization. Organic acid accumulation varied with wheat bran concentration (W) and soil depth; B: bottom layer, M: middle layer, and T: top layer. Organic acid concentration is per gram of dry soil.

Figure 7. Non-metric multidimensional scaling of soil bacterial communities. Shapes indicate time point and depth of soil samples. Shading describes the soil amendment treatment. 
Table 1. Average relative abundance of significant OTUs for microcosms with different wheat bran amendment concentrations (\%) after 15 days of solarization

\begin{tabular}{|c|c|c|c|c|c|c|c|}
\hline \multirow[b]{3}{*}{ OTU } & \multirow[b]{3}{*}{ Taxonomic classification } & \multicolumn{6}{|c|}{ Soil layer } \\
\hline & & \multicolumn{3}{|c|}{ Bottom and middle layers } & \multicolumn{3}{|c|}{ Top layer } \\
\hline & & $0 \%$ & $2 \%$ & $5 \%$ & $0 \%$ & $2 \%$ & $5 \%$ \\
\hline $\mathrm{X} 0$ & Gemmatimonadetes (CL) & 2.36 & 0.16 & 0.03 & 26.42 & 0.17 & 0.01 \\
\hline $\mathrm{X} 1$ & Ruminococcaceae (FA) & 0.00 & 13.40 & 16.92 & 0.00 & 2.02 & 0.42 \\
\hline $\mathrm{X} 2$ & Ureibacillus & 0.11 & 2.60 & 6.45 & 0.08 & 4.73 & 24.15 \\
\hline $\mathrm{X} 3$ & Steroidobacter & 8.26 & 0.06 & 0.05 & 3.77 & 0.04 & 0.00 \\
\hline $\mathrm{X} 4$ & Cytophaga & 2.35 & 0.05 & 0.10 & 8.45 & 0.19 & 0.00 \\
\hline $\mathrm{X} 5$ & Ruminococcaceae (FA) & 0.00 & 11.25 & 12.14 & 0.00 & 1.53 & 2.78 \\
\hline X6 & Chloracidobacteria (CL) & 4.19 & 0.03 & 0.02 & 1.05 & 0.01 & 0.00 \\
\hline $\mathrm{X} 7$ & Anaerolineae (CL) & 2.05 & 0.42 & 0.16 & 2.70 & 1.71 & 0.34 \\
\hline $\mathrm{X} 8$ & SHA-31 (FA) & 1.82 & 0.47 & 0.16 & 2.33 & 0.64 & 0.20 \\
\hline $\mathrm{X} 9$ & Bacillaceae (FA) & 0.13 & 0.99 & 5.63 & 0.08 & 0.93 & 10.70 \\
\hline $\mathrm{X} 10$ & Geobacillus & 0.00 & 5.79 & 10.15 & 0.00 & 1.08 & 0.33 \\
\hline $\mathrm{X} 11$ & Cytophaga & 0.01 & 1.33 & 0.21 & 0.08 & 0.87 & 0.00 \\
\hline $\mathrm{X} 12$ & Lachnospiraceae (FA) & 0.00 & 1.04 & 5.62 & 0.00 & 0.69 & 8.62 \\
\hline $\mathrm{X} 13$ & Planococcaceae (FA) & 0.72 & 0.91 & 1.32 & 0.51 & 1.86 & 4.52 \\
\hline X14 & Pseudoxanthomonas & 0.02 & 1.60 & 0.32 & 0.28 & 1.43 & 1.01 \\
\hline $\mathrm{X} 16$ & Streptomyces & 1.85 & 0.41 & 0.09 & 0.90 & 0.17 & 0.02 \\
\hline X19 & Actinomadura & 0.22 & 0.32 & 0.10 & 0.34 & 4.11 & 2.09 \\
\hline $\mathrm{X} 20$ & Leclercia & 0.00 & 2.15 & 4.33 & 0.03 & 0.49 & 2.18 \\
\hline \multirow[t]{2}{*}{$\mathrm{X} 32$} & Ruminococcaceae (FA) & 0.00 & 0.53 & 3.55 & 0.00 & 0.05 & 0.00 \\
\hline & $\%$ of total community & 24.10 & 43.52 & 67.34 & 47.03 & 22.72 & 57.39 \\
\hline
\end{tabular}

Taxonomic classification is given at the genus level unless otherwise indicated in parentheses (class, CL; family, FA). Shading reflects relative abundance with darker shades highlighting more abundant OTUs. The top soil layer exhibited marked differences from the middle and bottom layers and was disaggregated. Displayed OTUs were found to contribute to Bray-Curtis 
dissimilarity based on community comparisons according to both soil depth and wheat bran concentration. 
Table 2. Average relative abundance of significant OTUs in 5\% wheat bran microcosms at different soil depth after 15 days of solarization

\begin{tabular}{llcccc}
\hline & & & \multicolumn{3}{c}{ Soil depth } \\
\cline { 5 - 6 } OTU & Taxonomic classification & Inoculum & Bottom & Middle & Top \\
\hline X0 & Gemmatimonadetes (CL) & 0.17 & 0.04 & 0.01 & 0.01 \\
X1 & Ruminococcaceae (FA) & 0.00 & 19.99 & 13.85 & 0.42 \\
X2 & Ureibacillus & 0.15 & 0.03 & 12.87 & 24.15 \\
X3 & Steroidobacter & 1.14 & 0.08 & 0.02 & 0.00 \\
X4 & Cytophaga & 0.37 & 0.19 & 0.01 & 0.00 \\
X5 & Ruminococcaceae (FA) & 0.00 & 12.73 & 11.55 & 2.78 \\
X6 & Chloracidobacteria (CL) & 4.33 & 0.03 & 0.01 & 0.00 \\
X7 & Anaerolineae (CL) & 3.32 & 0.18 & 0.14 & 0.34 \\
X8 & SHA-31 (FA) & 3.17 & 0.21 & 0.11 & 0.20 \\
X9 & Bacillaceae (FA) & 0.16 & 1.64 & 9.61 & 10.70 \\
X10 & Geobacillus & 0.00 & 8.96 & 11.35 & 0.33 \\
X11 & Cytophaga & 0.00 & 0.24 & 0.18 & 0.00 \\
X12 & Lachnospiraceae (FA) & 0.00 & 3.36 & 7.88 & 8.62 \\
X13 & Planococcaceae (FA) & 1.42 & 0.75 & 1.89 & 4.52 \\
X14 & Pseudoxanthomonas & 0.02 & 0.17 & 0.48 & 1.01 \\
X16 & Streptomyces & 1.24 & 0.06 & 0.13 & 0.02 \\
X19 & Actinomadura & 0.19 & 0.05 & 0.14 & 2.09 \\
X20 & Leclercia & 0.00 & 7.15 & 1.51 & 2.18 \\
X32 & Ruminococcaceae (FA) & 0.00 & 7.02 & 0.08 & 0.00 \\
& \% of total community & 15.69 & 62.87 & 71.82 & 57.39 \\
\hline
\end{tabular}

Taxonomic classification is given at the genus level unless otherwise indicated in parentheses (class, CL; family, FA). Shading reflects relative abundance with darker shades highlighting more abundant OTUs. Displayed OTUs were found to contribute to Bray-Curtis dissimilarity based on community comparisons according to both soil depth and wheat bran concentration. 


\section{References:}

Achmon, Y., Harrold, D.R., Claypool, J.T., Stapleton, J.J., VanderGheynst, J.S., Simmons, C.W., 2016. Assessment of tomato and wine processing solid wastes as soil amendments for biosolarization. Waste management (New York, N.Y.) 48, 156-164.

Aslam, D.N., VanderGheynst, J.S., 2008. Predicting phytotoxicity of compost-amended soil from compost stability measurements. Environmental Engineering Science 25, 72-81.

Bhalla, A., Kainth, A., Sani, R., 2013. Draft genome sequence of lignocellulose-degrading thermophilic bacterium Geobacillus sp. strain WSUCF1. Genome Announc. 1, e00595-00513. Biddle, A., Stewart, L., Blanchard, J., Leschine, S., 2013. Untangling the Genetic Basis of Fibrolytic Specialization by Lachnospiraceae and Ruminococcaceae in Diverse Gut Communities. Diversity 5, 627.

Browning, M., Wallace, D.B., Dawson, C., Alm, S.R., Amador, J.A., 2006. Potential of butyric acid for control of soil-borne fungal pathogens and nematodes affecting strawberries. Soil Biology and Biochemistry 38, 401-404.

Doran, W.L., 1928. Acetic acid as a soil disinfectant. Journal of Agricultural Research 36, 269280.

Elmore, C.L., Stapleton, J.J., Bell, C.E., DeVay, J.E., 1997. Soil Solarization: A Nonpesticidal Method for Controlling Diseases, Nematodes, and Weeds. Publication 21377. University of California Division of Agriculture and Natural Resources, Oakland, CA, pp. 1-13.

EPA, 2012. Approval and Promulgation of Implementation Plans; California;

Revisions to the California State Implementation Plan Pesticide Element, in: Agency, U.S.E.P. (Ed.), EPA-R09-OAR-2012-0194.

Gamliel, A., Stapleton, J.J., 1993. Gamliel, A. and J. J. Stapleton. 1993. Effect of chicken compost or ammonium phosphate and solarization on pathogen control, rhizosphere microorganisms, and lettuce growth. Plant Disease 77, 886-891. Plant Disease 77, 886-891. Irvine, G., Lamont, E.R., Antizar-Ladislao, B., 2010. Energy from waste: Reuse of compost heat as a source of renewable energy. Int. J. Chem. Eng 2010, 1-10.

Kim, H.-L., Jung, B.-N., Sohn, B.-K., 2007. Production of weak acid by anaerobic fermentation of soil and antifungal effect. J Microbiol Biotechnol 17, 691-694.

Marshall, M.N., Rumsey, T.R., Stapleton, J.J., VanderGheynst, J.S., 2013. A Predictive Model for Soil Temperature During Solarization and Its Validation at Two California Field Sites. Transactions of the ASABE In press. McElderry, C.F., Browning, M., Amador, J.A., 2005. Effect of Short-Chain Fatty Acids and Soil Atmosphere on Tylenchorhynchus spp. J of Nematology 37, 71-77.

Momma, N., Yamamoto, K., Simandi, P., Shishido, M., Role of organic acids in the mechanisms of biological soil disinfestation (BSD). Journal of General Plant Pathology 72, 247-252.

Ramirez-Villapudua, J., Munnecke, D.E., 1988. Effect of solar heating and soil amendments of cruciferous residues on Fusarium oxysporum $\mathrm{f}$. sp. conglutinans and other microorganisms. . Phytopathology 78, 289-295.

Simmons, C.W., Claypool, J.T., Marshall, M.N., Jabusch, L.K., Reddy, A.P., Simmons, B.A., Singer, S.W., Stapleton, J.J., VanderGheynst, J.S., 2014. Characterization of bacterial communities in solarized soil amended with lignocellulosic organic matter. Applied Soil Ecology 73, 97-104. 
Simmons, C.W., Guo, H., Claypool, J.T., Marshall, M.N., Perano, K.M., Stapleton, J.J., VanderGheynst, J.S., 2013. Managing compost stability and amendment to soil to enhance soil heating during soil solarization. Waste Management 33, 1090-1096.

Sreenarayanan, V.V., 1986. Specific heat of rice bran. Agr. Wastes 16, 217-224.

USEPA, 2011. Ozone Layer Protection - Regulatory Programs. EPA.

Vital, M., Howe, A., Tiedje, J., 2014. Revealing the bacterial butyrate synthesis pathways by analyzing (meta)genomic data. mBio 5, e00889-00814.

Zainudin, M.H.M., Hassan, M.A., Tokura, M., Shirai, Y., 2013. Indigenous cellulolytic and hemicellulolytic bacteria enhanced rapid co-composting of lignocellulose oil palm empty fruit bunch with palm oil mill effluent anaerobic sludge. Bioresource Technology 147, 632-635. 

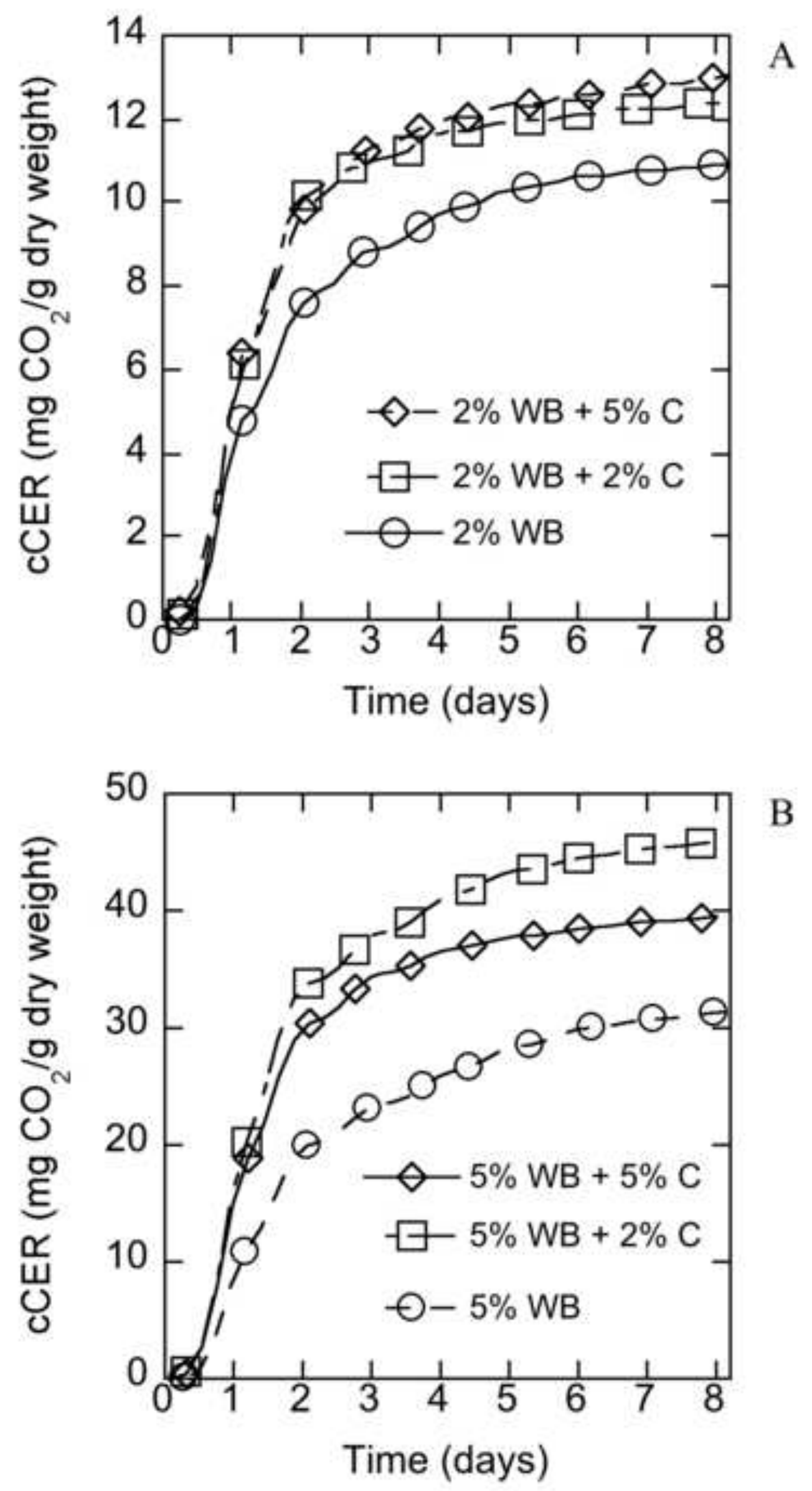


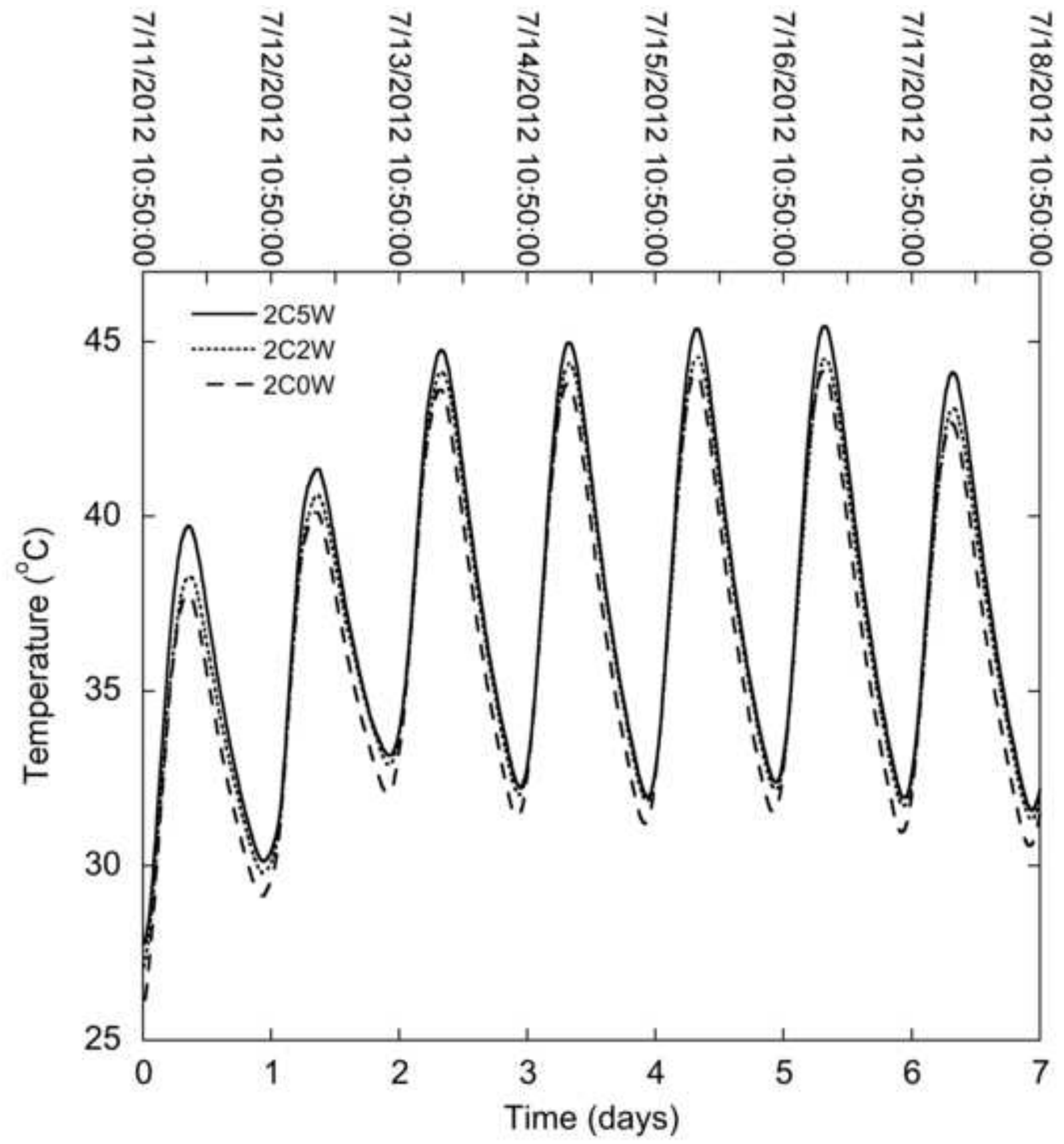




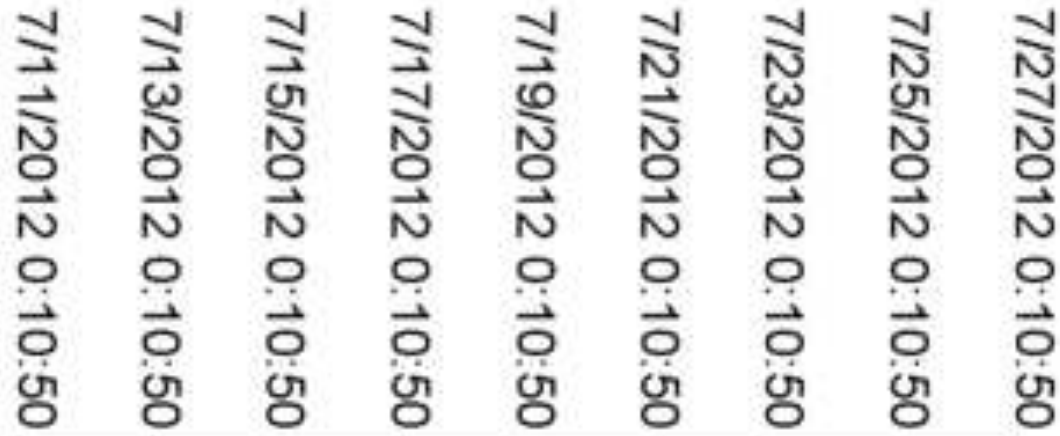
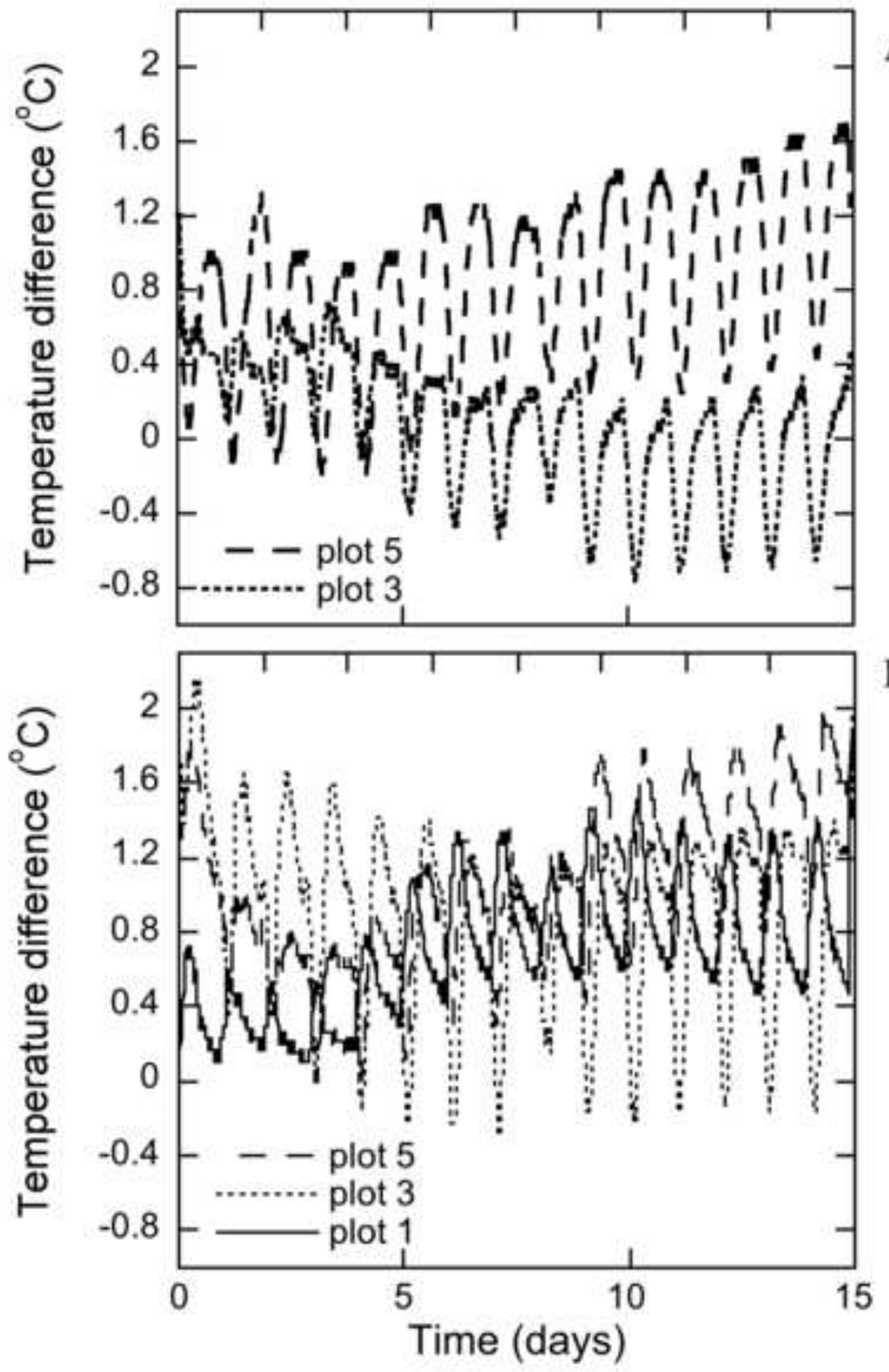


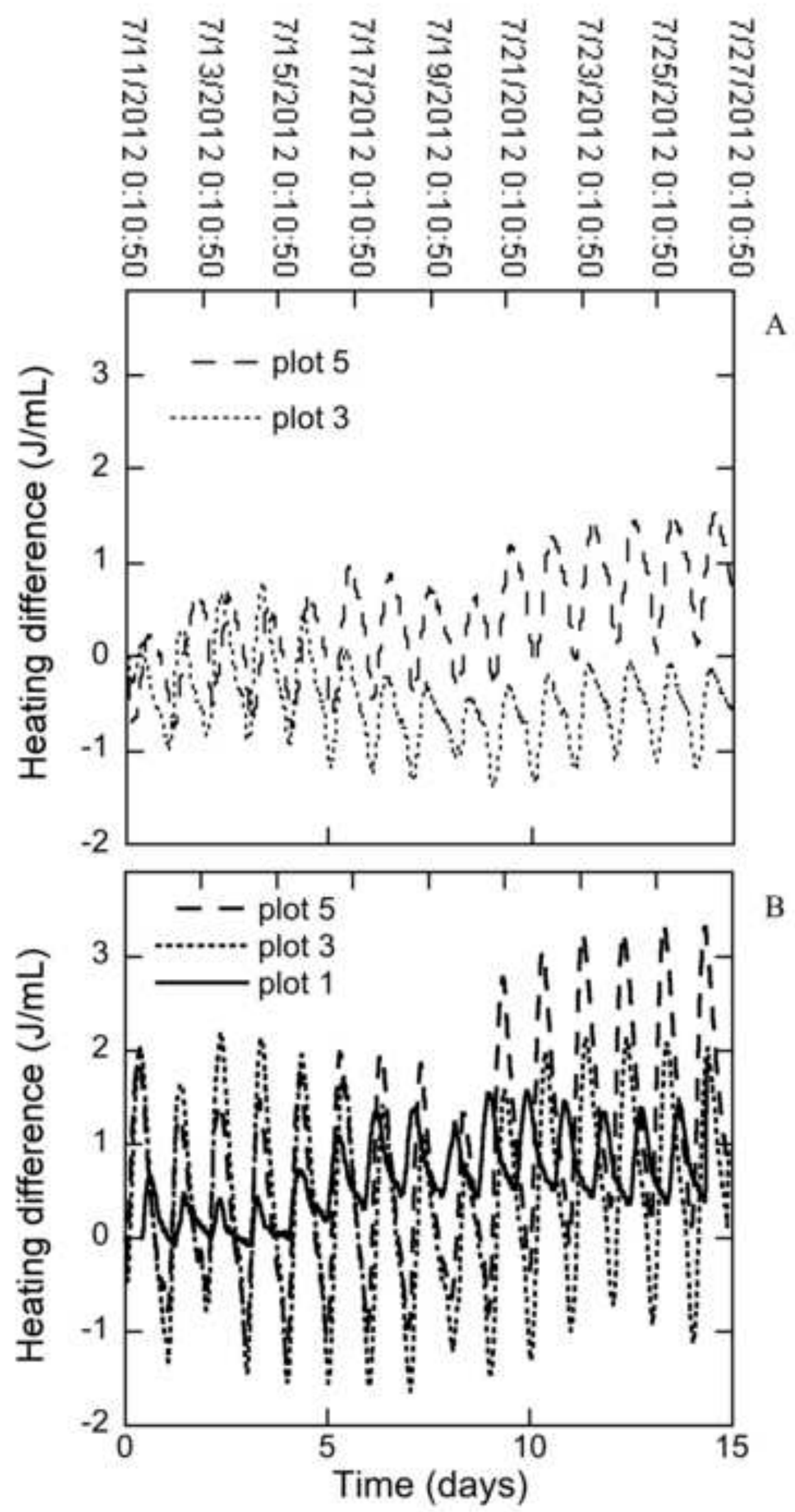




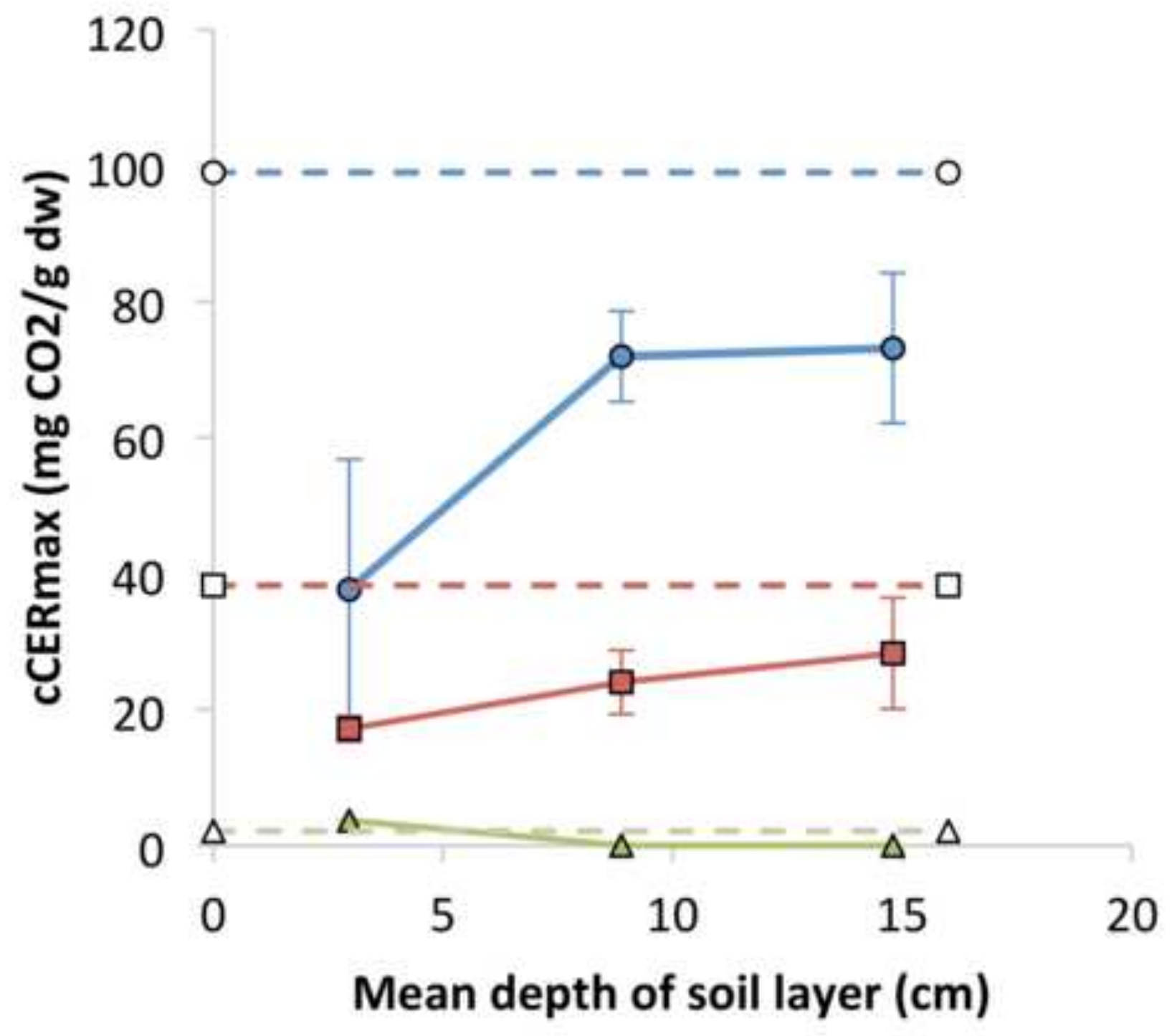

- $-5 \%$ wheat bran, solarized

$-\square-2 \%$ wheat bran, solarized

$-\Delta \%$ wheat bran, solarized

- $0-5 \%$ wheat bran, freshly mixed

$-\square-2 \%$ wheat bran, freshly mixed

$-\Delta-0 \%$ wheat bran, freshly mixed 


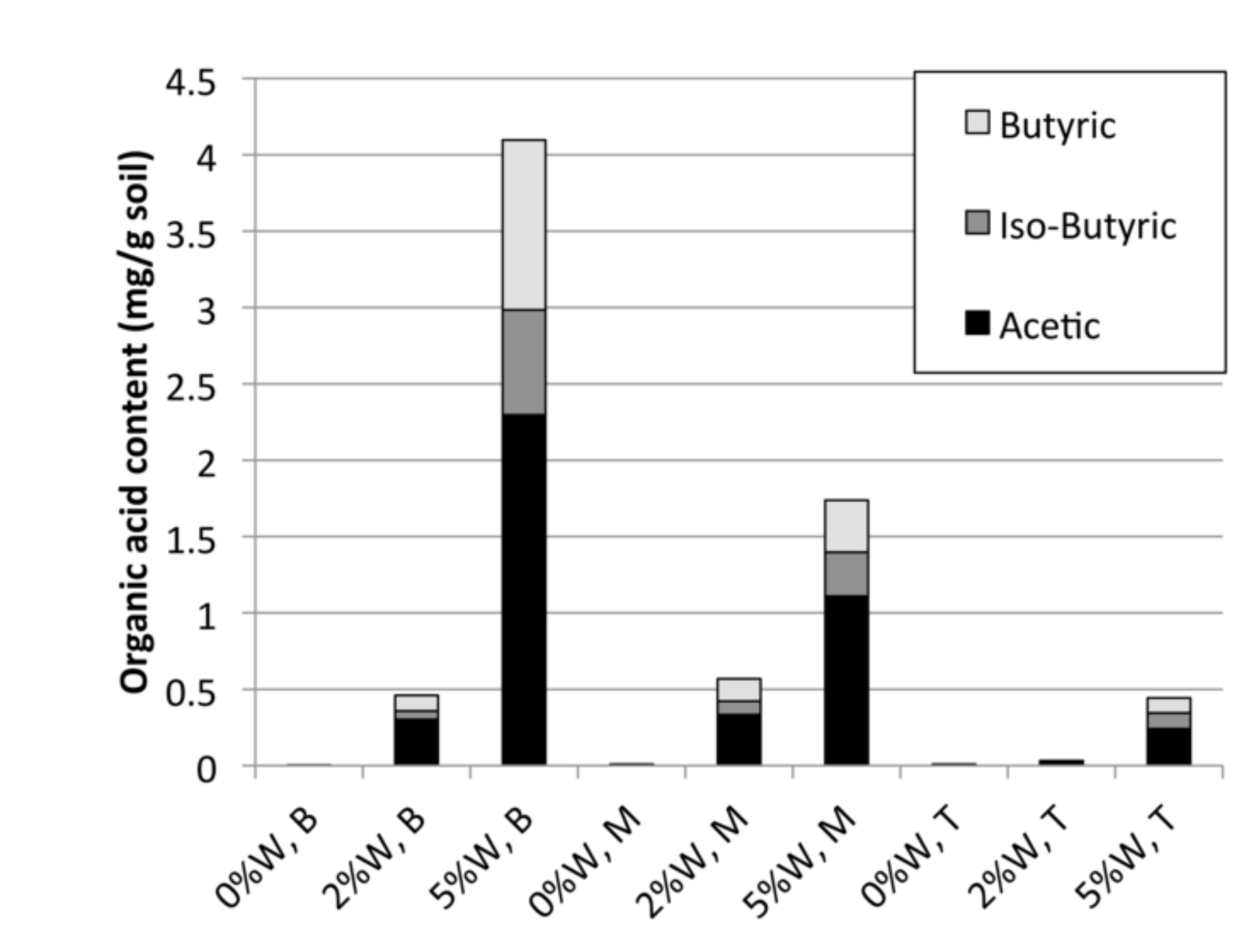




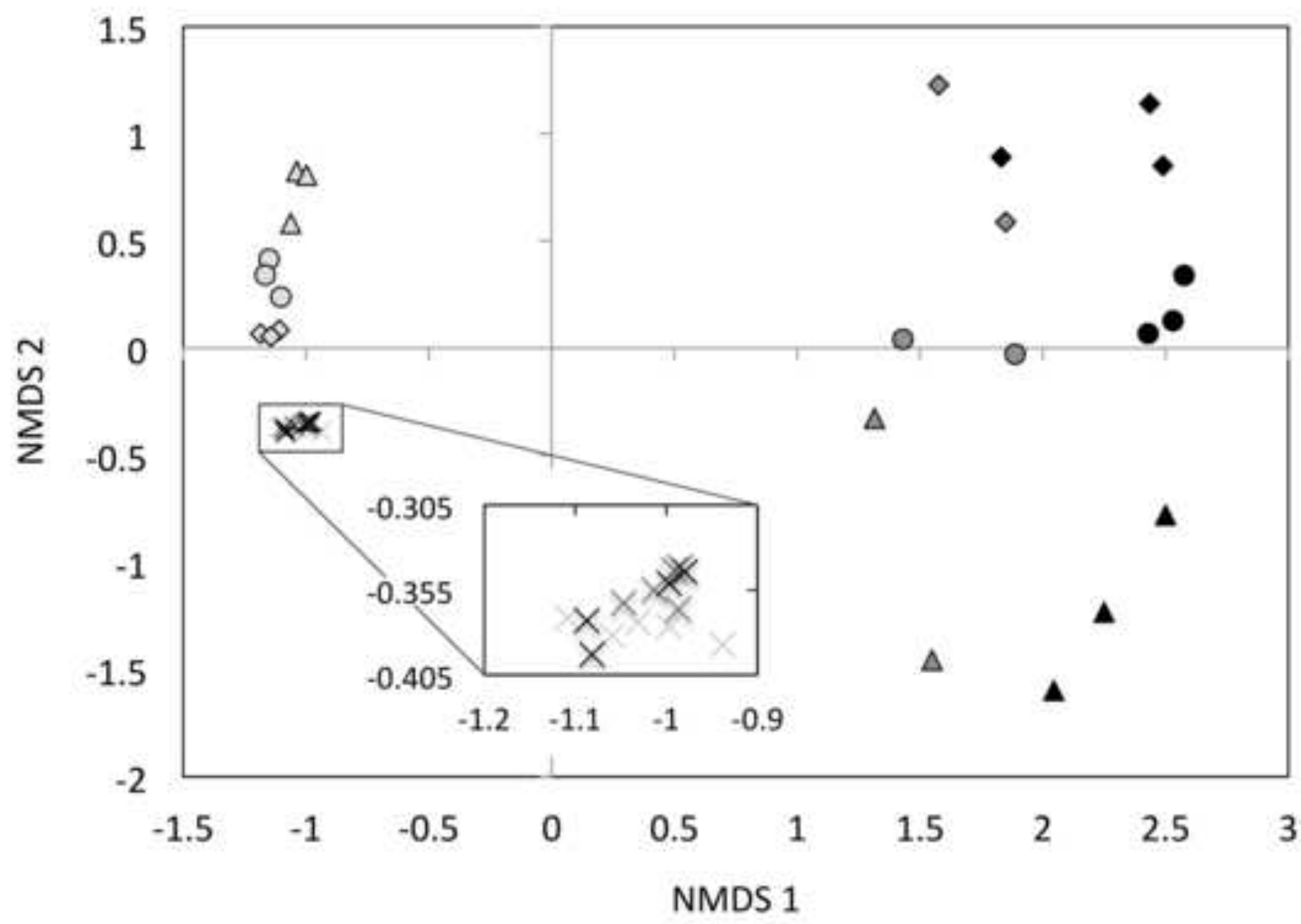

$\times$ Pre-solarization

$\diamond$ Post-solarization

$\checkmark$ Bottom layer

Post-solarization

Middle layer

Post-solarization

$\triangle$ Top layer

$\square 0 \%$ Wheat bran

$\square 2 \%$ Wheat bran

口 $5 \%$ Wheat bran 3 NMDS 1 